\title{
Assessing spatial variations of groundwater arsenic with surface elevation, slope and water-table using geospatial techniques in Ballia district, India
}

\author{
Tabrez Alam Khan ${ }^{1}$ Atiqur Rahman ${ }^{2} \cdot \operatorname{Imran}_{\mathrm{Ali}^{1}}{ }^{1}$ Joheb Khan ${ }^{3}$. \\ Syed Dilshad Alam ${ }^{1}$
}

Received: 14 April 2016/Accepted: 22 April 2016/Published online: 11 May 2016

(c) Springer International Publishing Switzerland 2016

\begin{abstract}
The present study describes spatial variation of arsenic (As) in groundwater with respect to surface elevation and slope using SRTM data. In total, 34 water samples were collected from shallow aquifers covering all 17 blocks of Ballia district in the pre and post-monsoon season during 2011. Atomic absorption spectrophotometer (AAS) was used for arsenic testing. Inverse Distance Weighted (IDW) model was applied for interpolation of As concentrations. The statistical method was applied to assess the spatial variations amongst the variables. The result showed that the highest arsenic concentrations were found at low surface elevation, slopes and water table. The results also show the inverse relationship among these variables. The relationships between groundwater arsenic, slopes and water table were non-linear. These variables had negative corrections with As in groundwater. The study showed that
\end{abstract}

Atiqur Rahman

ateeqgeog@yahoo.co.in

Tabrez Alam Khan

takhan@jmi.ac.in

Imran Ali

rimran_ali@yahoo.com

Joheb Khan

joheb_khan84@yahoo.com

Syed Dilshad Alam

dilshad826@gmail.com

1 Department of Chemistry, Faculty of Natural Sciences, Jamia Millia Islamia, New Delhi-25, India

2 Department of Geography, Faculty of Natural Sciences, Jamia Millia Islamia, New Delhi-25, India

3 Department of Geography, Banasthali University, Rajasthan, India more than $90 \%$ areas contain arsenic above the permissible limit of $10 \mathrm{ppb}$ in both pre- and post monsoon seasons.

Keywords Ground water - Arsenic - Geomorphic features · SRTM satellite data $\cdot$ GIS · Ballia-India

\section{Introduction}

Groundwater is one of the most important sources of water supply. Arsenic (As) contamination of groundwater is a major global concerns (Ali et al. 2012b). Groundwater is being contaminated by As due to various anthropogenic sources (Ghosh and Singh 2009). Ground water is getting poisonous due to As contamination and a big chunk of people are dependent of water which has high concentration of As (Rahman et al. 2015a). Large population in parts of flood plains of Padma and Meghna rivers in Bangladesh (Dhar et al. 1997), China, Vietnam, Nepal and the Indian plains of Ganges and Ganga-Meghna-Brahmaputra (Tripathi 2008; Kinniburgh and Smedley 2001) are badly affected due to high arsenic concentration in the groundwater (Brammer and Ravenscroft 2009). The As in groundwater is a big problem in several parts of India and other neighbouring countries (Rahman et al. 2015b). The state of West Bengal is suffering from arsenic problem for years (Chowdhury et al. 1999). Lakhimpur and Golaghat districts in Assam had arsenic concentrations above $50.0 \mu \mathrm{g} \mathrm{L}^{-1}$ (Chakraborti et al. 2004). The groundwater in North-Eastern states including Bihar has been polluted, which has spread to Ballia, Ghazipur and Varanasi districts in eastern Uttar Pradesh (Ahamed et al. 2006). Arsenic contamination in groundwater above the permissible limit of $10 \mathrm{ppb}$ (WHO and BIS guidelines) in the flood plains of Bengal, Bihar, Uttar Pradesh and Manipur, etc. 
(Chakraborti et al. 2002; Chauhan et al. 2012) adversely affecting around 1.25 million people in six blocks of Murshidabad district, West Bengal (Samadder 2010).

Shamsudduha and Uddin (2007) examined the spatial and vertical distribution of As contamination and its relationship with surface elevation in alluvial aquifers of the Bengal Basin. The distribution of As in groundwater was found to be directly controlled by topography and high As concentrations were found in low lying deltaic areas where water-tables were low. Shamsudduha et al. (2009) assessed the spatial variation of groundwater As with surface topography and water-table. Another study suggested that finer sediments with As bearing minerals and organic matter might be the cause of high As concentrations in groundwater, which are accumulated due to static groundwater and low surface elevation within low watertable (Shamsudduha et al. 2009; Mukherjee et al. 2007). Widespread As problem in the groundwater in Bangladesh has been examined by using geo-statistical and multivariate techniques (Shamsudduha 2004). The hydrological control of As concentrations in groundwater in Bangladesh has been studied (Stute et al. 2007). The spatial extent and depth range of low As in groundwater across Bangladesh were estimated by mapping the associations of low As concentration in groundwater with topography, water table elevation, surface sediment lithology, geology and screen depth of deep wells in low As zones within the aquifers (Hoque et al. 2011). Groundwater dynamics and arsenic mobilization has been examined using noble gases and tritium in Bangladesh (Klump et al. 2006).

Arsenic pollution in the groundwater and its impact on water quality and human health has been studied in the Simav Plain of Turkey (Gunduz et al. 2010). The effect of As pollution in drinking water in blocks of Murshidabad district, is assessed using GIS technology, revealed that life expectancy at birth and at other age groups was badly affected (Samadder 2010). GIS technique with a combination of classification tree method is applied to prepare an As contamination risk map for the groundwater As contamination risk prediction (Hossain and Piantanakulchai 2013). Although the anthropogenic source of As contamination is increasingly becoming important yet much of As problem in Bangladesh and West Bengal is due to aquifer geology (Mahimairaja et al. 2005).

Arsenic ranging from 0 to $468 \mathrm{ppb}$ and 12 to $20 \mathrm{ppb}$ were reported in groundwater samples of shallow and deep aquifers in Ballia (Chauhan et al. 2009) and As concentration, i.e., 73, 47, 15, and $129 \mathrm{ppb}$ in water samples of four hand pumps in Ballia (CSE 2005). Out of 72 samples from shallow, medium and deep aquifers in Belehari and Bairia blocks of Ballia district 52 samples had As above $50 \mathrm{ppb}$ (Tripathi 2008) which shows the extent and magnitude of As in groundwater in Ballia district. Topography of Ballia district is flat to gentle with seasonal water-table fluctuations. Physiographically the district comes under the central Gangetic plain where topography is flat to gentle undulation due to palaeo-channels. The major landforms in the district are flood plain, younger and older alluvial plain (Tripathi 2008). Although As has been reported in both older and younger alluvium plains yet high concentrations were reported in younger alluvium plain. Because the younger alluvium is not oxidized in nature; and has organic-rich sand silt and clay, which favour the accumulation of As rich minerals (Acharyya and Shah 2007; Chauhan et al. 2009). The younger alluvium plains are restricted all along the river channels of the Ganges River. As bearing pyrite minerals are transported with the fluvial erosion from the Himalayas along with the Ganges River. During the course of time, these minerals get deposited and younger alluvium plains formed. This may be the basic source of As contamination into the groundwater of Ballia district. Small amounts of As enter the soil and water through various biological sources (biogenic) that are rich in As.

Various studies have been carried out on the geochemical aspects of As in different places but no work has been done involving the physical aspect in Ballia district, which is the most affected district of Uttar Pradesh. Based on the above discussion the main aim of the paper is to study the spatial relationship of groundwater As with topography, elevation, slope and water-table in shallow aquifers in preand post monsoon seasons in Ballia district by using the satellite data and GIS technique.

\section{Study area}

Ballia district is situated in the eastern-most part of Uttar Pradesh. The district is located between $25^{\circ} 23^{\prime \prime}$ to $26^{\circ} 11^{\prime \prime} \mathrm{N}$ and $83^{\circ} 38^{\prime \prime}$ to $84^{\circ} 39^{\prime \prime} \mathrm{E}$. It has an area of about $2981 \mathrm{~km}^{2}$. There are six tehsils in Ballia district viz. Sikanderpur, Ballia (Sadar), Rasra, Belthra, Bairia and Bansdih. There are seventeen blocks viz. Bansdih, Belhari, Bairiya, Chilkahar, Dubhad, Nagra, Rasra, Siar, Navanagar, Pandah, Maniyar, Veruarwari, Revati, Garwar, Sohaon, Hanumanganj, and Murlichapra (Census of India 2001). The district is surrounded by three rivers, the Ghaghara in the north and the Chhoti Saraju and Ganges in the south (Fig. 1). There are an interfluves zone of the Ghaghara and the Ganges rivers. The district has sub-humid type of climate conditions. There are three seasons, i.e., cold, hot, and the monsoon seasons (Tripathi 2008). The mean maximum monthly temperature is $41.7^{\circ} \mathrm{C}$ during May and minimum is $22.8{ }^{\circ} \mathrm{C}$ in January. The average rainfall of the district is $983 \mathrm{~mm}$. Agriculture is the main stay of the district's economy. The main source of irrigation is tube wells and canals with Doharighat Lift Irrigation canal is the main canal. 


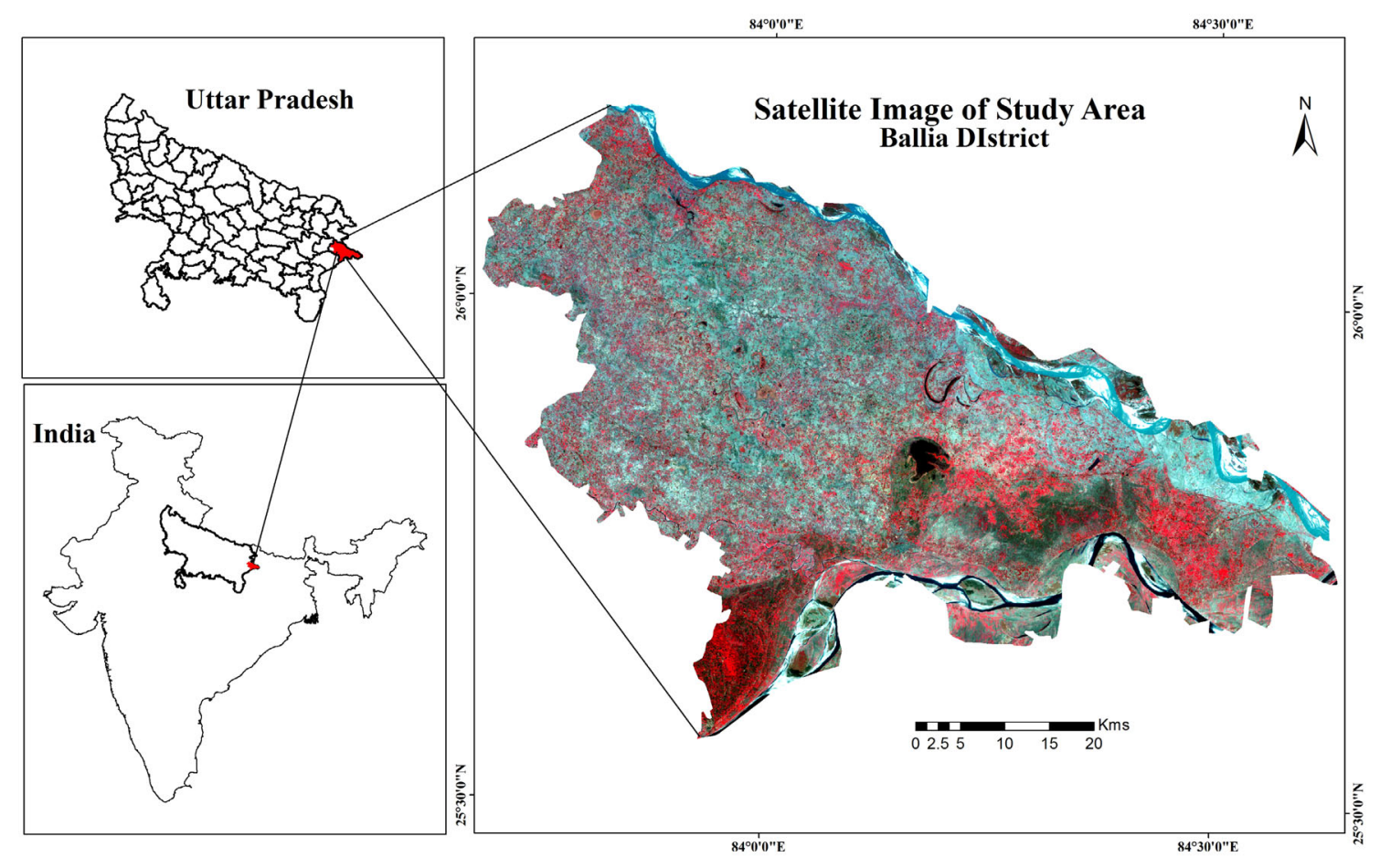

Fig. 1 Locational aspects of the study area

Geologically, Ballia district is a part of central alluvial plain covered with the Ganga alluvium, which is conventionally subdivided into two types of Gangetic alluvium plain. One is older alluvium of Pleistocene age is 2.588-12 million years before from present and second is younger or newer alluvium of Holocene age 11,700 years to present. The surface elevation in the district ranges from 27 to $115 \mathrm{~m}$ and in eastern parts of Ballia have higher elevation than the western part. Topographic slope ranges from 0 to $12 \%$ in the district. Groundwater in the district occurs under unconfined and semi-confined conditions. Water table varies from 0.60 to $8.12 \mathrm{~m} \mathrm{bgl}$ in pre-monsoon and 0.85 to $6.49 \mathrm{~m} \mathrm{mbgl} \mathrm{in} \mathrm{post-monsoon} \mathrm{period} \mathrm{in} \mathrm{unconfined}$ condition. The groundwater flow in unconfined condition is from west to east (Tripathi 2008).

\section{Material and method}

\section{Shuttle radar topography mission (SRTM) digital elevation (DEM) dataset}

The SRTM-DEM data of $90 \mathrm{~m}$ spatial resolution is useful to collect information of height at a particular scale of any part of Earth surface (USGS 2002). DEM contains elevation information in its each pixel, which is useful for topography mapping. Therefore; SRTM-DEM has been downloaded from Global Land Cover Change Facility
(GLCF) using the link http://glcf.umd.edu and this data is converted into raster format to generate slope and aspect. Thereafter, slope and aspect have been derived from SRTM-DEM images of August 2010. As values is overlaid on the slope and topography, to draw the inter relationships. The detailed flow chart of methodology is shown in Fig. 2.

\section{Groundwater level (water table)}

Water table map was prepared both for pre and postmonsoon seasons of 2011 using bore well data taken from the Ballia district water works (Jalnigam) and Central Groundwater Board (CGWB) department. The measurements of water level were also done from open wells using the magnetic tape. Thereafter, water table maps were prepared in GIS environment using inverse distance weightage interpolation (IDW) model.

\section{Water sampling and analysis}

Thirty-four water samples from shallow $(<25 \mathrm{~m})$ aquifers were collected covering whole Ballia district (Fig. 3). Premonsoon water samples were collected in April, 2011 and in December, 2011 for post-monsoon. These samples were collected in a $500 \mathrm{~mL}$ of polyethylene bottles for As analysis. Before sampling, the hand pumps were flushed with $35-45 \mathrm{~L}$ of water and then $1.0 \mathrm{~mL}$ of conc. $\mathrm{HNO}_{3}$ was 


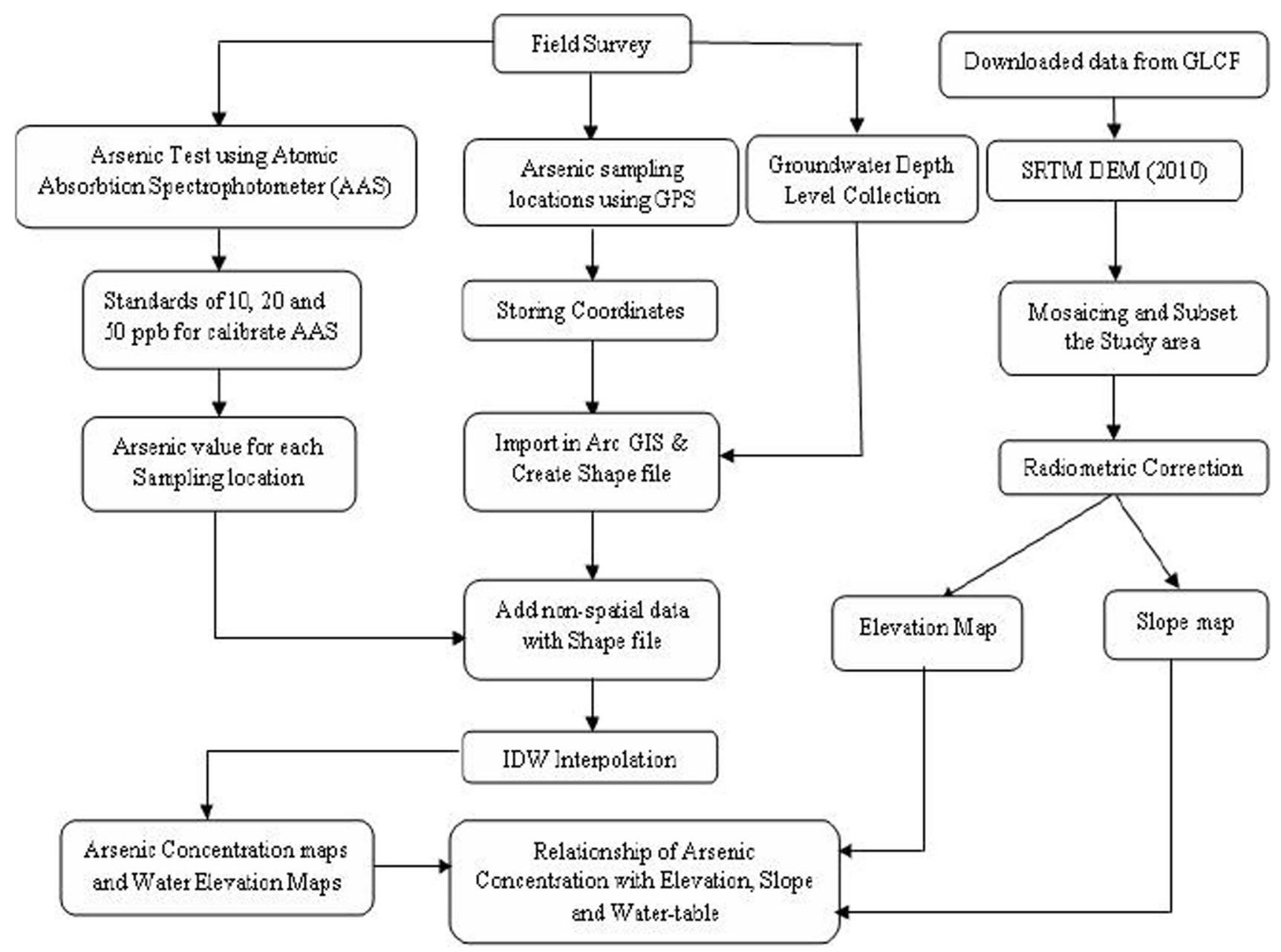

Fig. 2 Flow chart of methodology for testing and modeling of arsenic

added to $500 \mathrm{~mL}$ sample bottles to preserve As and stored in refrigerator. Water samples were filtered through $0.45 \mu \mathrm{m}$ and stored at $4{ }^{\circ} \mathrm{C}$ in polyethylene for analyses within 10 days of sample collection.

The water samples were analysed by atomic absorption spectrophotometer (AAS). Sodium arsenate $\left(\mathrm{Na}_{2} \mathrm{HAsO}_{4} 7\right.$ $\mathrm{H}_{2} \mathrm{O}$ ), hydrochloric acid, nitric acid and the deionised water were used for water analysis. The deionised water was prepared by Millipore purification system. The standards of As of 10, 20, and $50 \mathrm{ppb}$ were prepared to calibrate atomic absorption spectrometers. The linearity curve was plotted with determination of limit of detection. The analyses of arsenic was carried out using five replicates $(n=5)$.

Water samples were pre-concentrated to achieve the concentration of arsenic under the detection limit of instrument $(10 \mathrm{ppb})$. One liter water sample was evaporated to $50 \mathrm{~mL}$. The quality assurance protocol was adopted as per standard methods and its outcome was measured in terms of precision and accuracy [Methods for Flame and Graphite
Furnace Atomic Absorption Spectroscopy (Recommended Reasonable Confidence Protocols, Quality Assurance and Quality Control Requirements), Determination of Metals by SW-846 7000 Series, Department of Environmental Protection, Version 2.0, State of Connecticut, USA, July 2006.]. The results of the statistical analyses of the experimental data such as standard deviation, correlation coefficients and confidence limit were calculated. Good linearity of the calibration graphs and the negligible scatter of experimental points were considered for calculations of correlation coefficients and relative standard deviations. The standard deviation ranged 0.5 to 1.0 . The limit of detection was $10.0 \mathrm{ppb}$. The accuracy ranged 0.1 to 0.3 as relative error (Fig. 4).

\section{Geo-spatial analysis}

Water sampling locations were determined by a portable Garmin GPS (Global Positioning System) with 4-6 $\mathrm{m}$ accuracy. The latitude, longitude and altitude were 


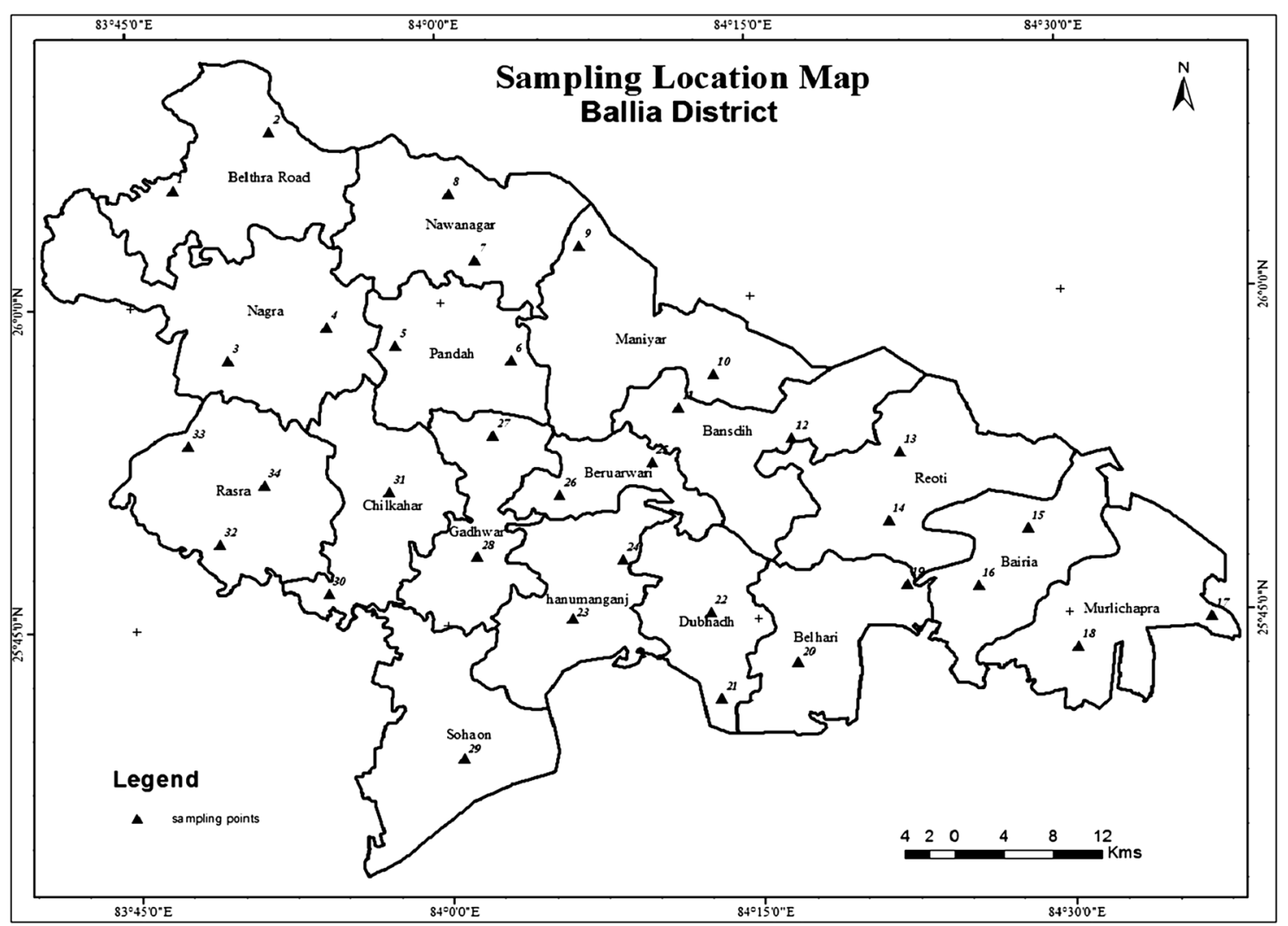

Fig. 3 Ground water sampling locations

recorded in degrees decimal and imported in excel files using Map Source software. All the coordinates of sampling locations were imported in Arc GIS software. Nonspatial data (As values) were added with spatial data, i.e., point feature shape files. Tested As values of all 34 samples from 17 blocks were interpolated using inverse distance weighted (IDW) model in order to assess the spatial variation of As in the study area. Groundwater elevation data collected from the field survey were used to create water level maps using IDW model (Fig. 2) for both pre- and post-monsoon seasons of 2011. There was evidence of seasonal variation in concentrations of As between pre and post-monsoon seasons (Ali et al. 2012a).

Two SRTM images were mosaiced using Erdas imagine software to get one image file of DEM and then study area was sub-set. Image enhancement and radiometric correction were done to enhance the image quality for better interpretation and analyses. The district has flat to undulation topography, sinks or depressions in low-lying areas are not associated with water bodies and wetlands in floodplains. By removing negative values (associated with river channels) and artificial topographic sinks from the SRTM data, a more reliable DEM can be generated with the same spatial resolution of $90 \mathrm{~m} \times 90 \mathrm{~m}$ for GIS analysis (Jarvis et al. 2006). Therefore, in our study these sinks or depressions were filled using the spatial analyst tool of Arc GIS software based on Jarvis et al. (2006). Topographic slope was derived from DEM using surface analysis of 3D analyst tool, it is seen that Ballia district lies in low-lying floodplains with small variation in slope at the banks of Ghaghara and Ganges rivers.

\section{Statistical analysis}

In this paper the descriptive statistical analysis has been done to assess the relationships of groundwater arsenic with surface elevation, slope, and water table. As per BIS and WHO standard, the permissible limit of As in groundwater is $10 \mathrm{ppb}$. Therefore, tested As values has been categorised into three classes, i.e., $<10,10-15$, and $>15 \mathrm{ppb}$. Scatter plots were prepared to determine the relationship among these variables and correlation coefficients has been calculated.

\section{Results and discussion}

\section{Surface elevation and groundwater As concentration}

Spatial relationship has been drawn between surface elevation derived from DEM and groundwater As level 


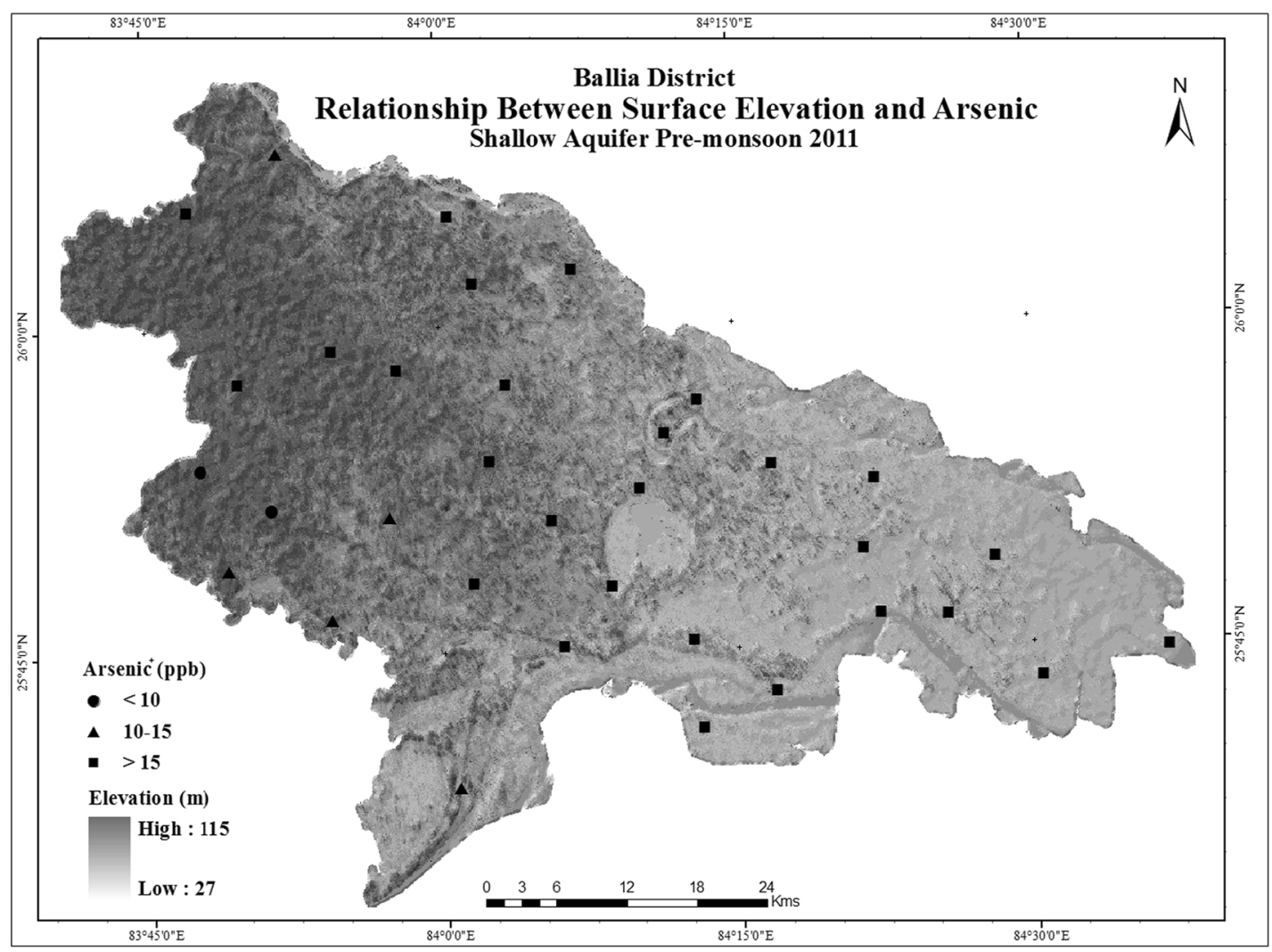

Fig. 4 Relationships between surface elevation and arsenic pre-monsoon

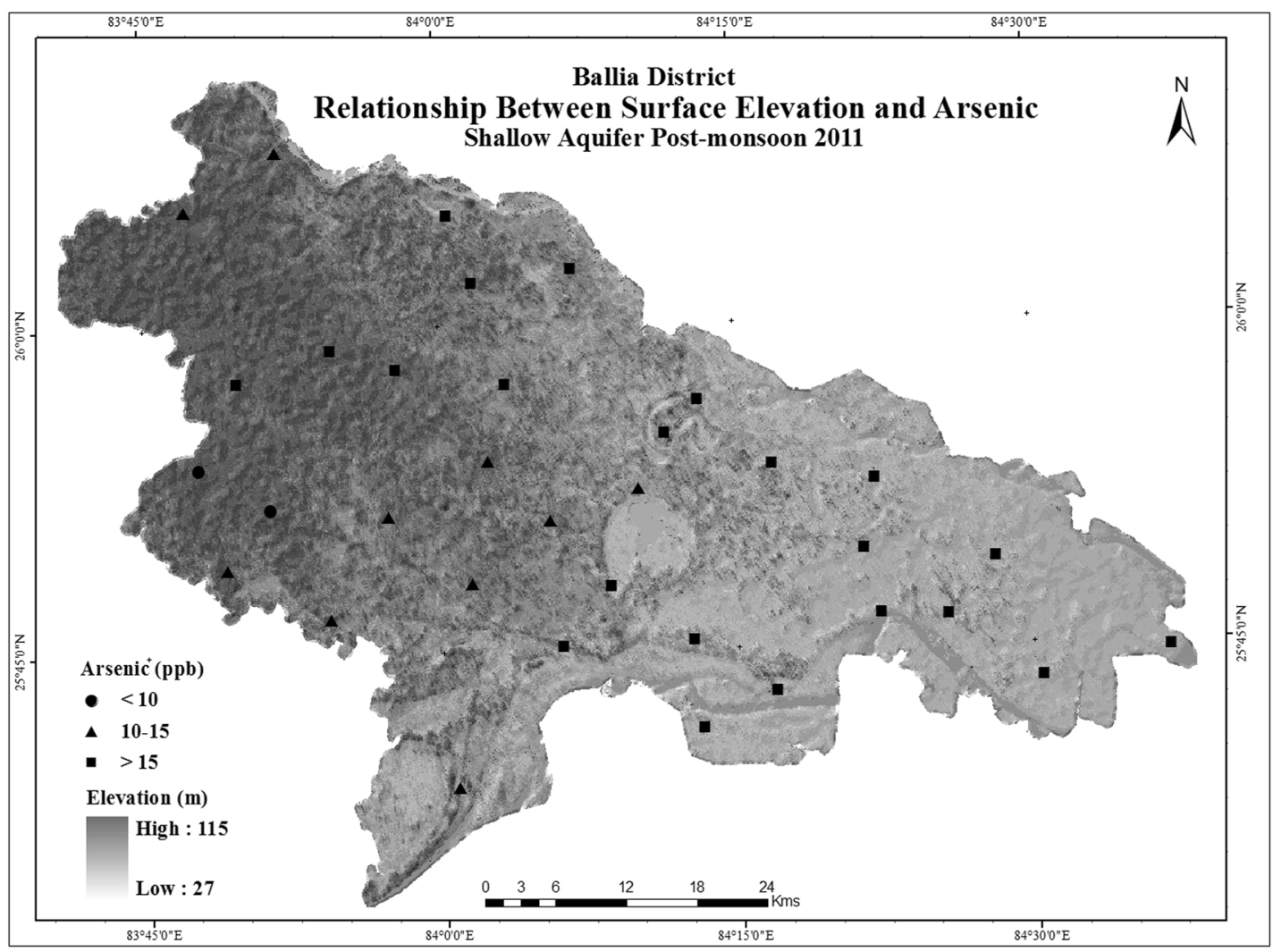

Fig. 5 Relationships between surface elevation and arsenic post-monsoon 


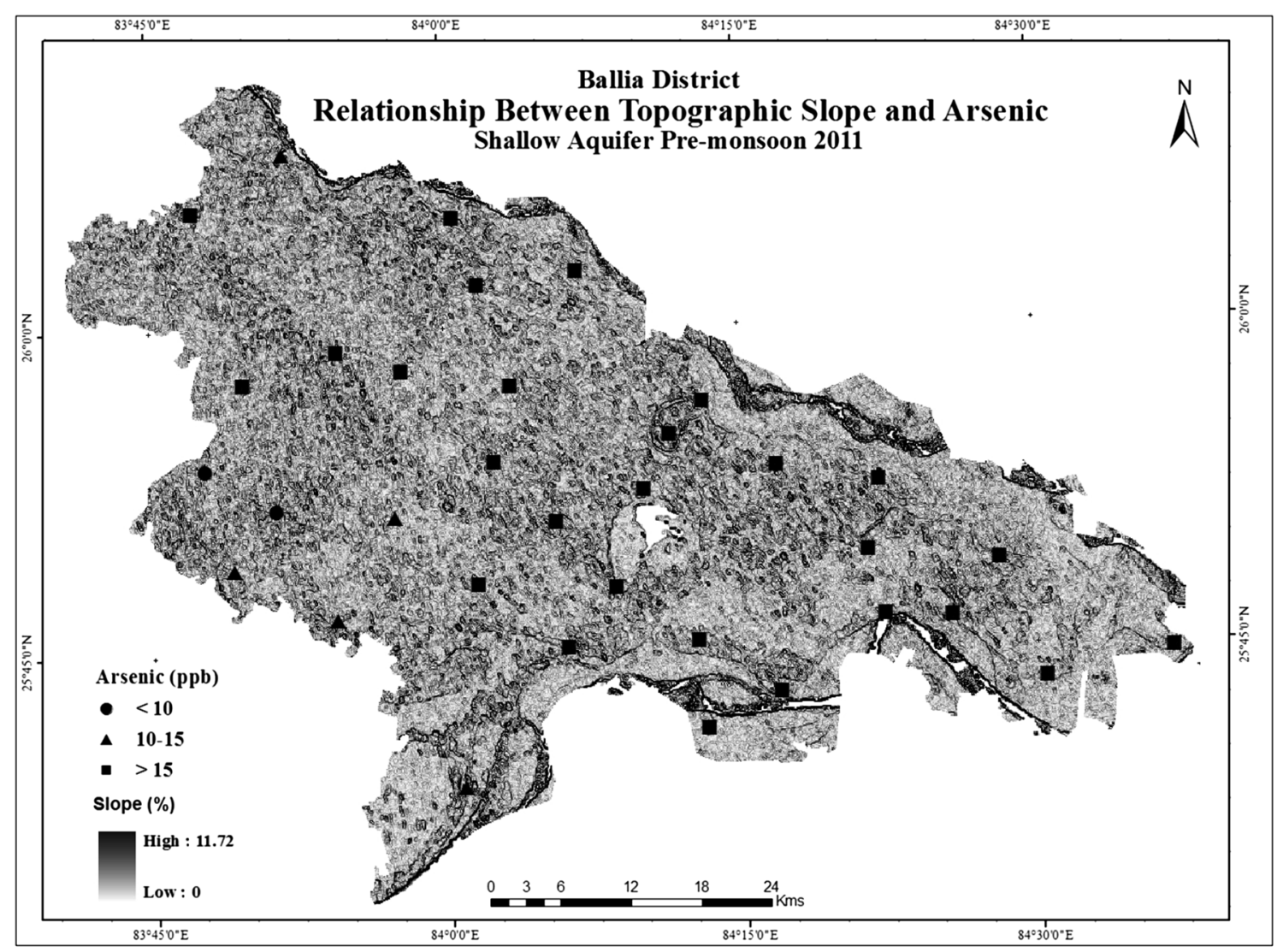

Fig. 6 Relationships between topographic slope and arsenic pre-monsoon

(Figs. 5, 6). The study shows at the higher surface elevation $(72-73 \mathrm{~m})$ As is within the permissible limit of $10 \mathrm{ppb}$ but such area is just $6 \%$, i.e., $175 \mathrm{sq} \mathrm{km}$ of the total district. Whereas in $2806 \mathrm{sq} \mathrm{km}(94 \%)$, i.e., $2367 \mathrm{sq} \mathrm{km}$ in pre and $1929 \mathrm{sq} \mathrm{km}$ area post monsoon have As $>15 \mathrm{ppb}$ where elevation is between 56 to $73 \mathrm{~m}$ (Table 1). The scatter plots between As and surface elevation shows that the correlation coefficient $\left(\mathrm{r}^{2}\right)$ values were $(0.89)$ and $(0.76)$ in pre and post-monsoon seasons, respectively (Fig. 10). This shows that the relationship is non-linear and groundwater As and surface elevation high positive correlation. This means that the surface topography is inversely related with As concentration in the study area. The areas with low surface elevation have high As concentration and areas with relatively high surface elevation have low As concentration. This closely relates with the mean surface elevation of 64.33 and $63.68 \mathrm{~m}$, i.e., 80 and $65 \%$ of the total area have As more than $15 \mathrm{ppb}$ in pre and post-monsoons, respectively (Table 1).

\section{Topographic slope and groundwater As concentration}

Another spatial relationship has been drawn between topographic slope derived from DEM and groundwater
As in pre and post-monsoon seasons (Figs. 6, 7). Arsenic contamination in drinking water and the coincidence of risk areas has been studied in relation with low relief topography (Buschmann et al. 2007). Slope is directly related with surface elevation, this means low slopes are found where surface elevation is low and vice versa. The relationship between groundwater As and slope in shallow aquifer showed that $2806 \mathrm{sq} \mathrm{km}$ area have As above the permissible limit of $10 \mathrm{ppb}$ both in pre and postmonsoon seasons (Table 2). About 439 and $877 \mathrm{sq} \mathrm{km}$ areas come under $10-15 \mathrm{ppb}$ As concentrations in pre and post monsoons, where the mean slope is 1.37 and $1.10 \%$. The scatter plots showed the correlation coefficients $\left(\mathrm{r}^{2}\right)$ between As and topographic is $(0.73)$ and (0.68) in pre and post-monsoons, respectively (Fig. 10). The relationship between As and topographic slope is non-linear suggesting that these two variables have positive correlation. This closely relates with the mean slope of 0.66 and $0.63 \%$, i.e., 2367 and 1929 sq km area of aquifers was highly contaminated with $>15 \mathrm{ppb}$ As concentration (Table 2). This means that the slope is inversely related with As distribution. Therefore, aquifers with low concentrations of As was also found in high slope areas and high As values are found in the areas of low slope. 
Table 1 Relationship between surface elevation and As concentration in shallow aquifer (pre and post-monsoon season)

\begin{tabular}{|c|c|c|c|c|c|c|}
\hline \multirow[t]{2}{*}{ Statistical parameters } & \multicolumn{2}{|c|}{ As $<10 \mathrm{ppb}$} & \multicolumn{2}{|c|}{ As $10-15 \mathrm{ppb}$} & \multicolumn{2}{|c|}{ As $>15 \mathrm{ppb}$} \\
\hline & Pre & Post & Pre & Post & Pre & Post \\
\hline Number of As data points & 2 & 2 & 5 & 10 & 27 & 22 \\
\hline As-affected area (in sq km) & 175 & 175 & 439 & 877 & 2367 & 1929 \\
\hline Range (surface elevation in $\mathrm{m}$ ) & $72-73$ & $72-73$ & $70-75$ & $62-75$ & $56-73$ & $56-73$ \\
\hline Mean elevation (m) & 72.5 & 72.5 & 72 & 69.6 & 64.33 & 63.68 \\
\hline $95 \%$ confidence interval & 0.79 & 0.79 & 0.68 & 0.65 & 0.57 & 0.51 \\
\hline Standard deviation & 0.5 & 0.5 & 1.67 & 3.50 & 4.68 & 4.72 \\
\hline
\end{tabular}

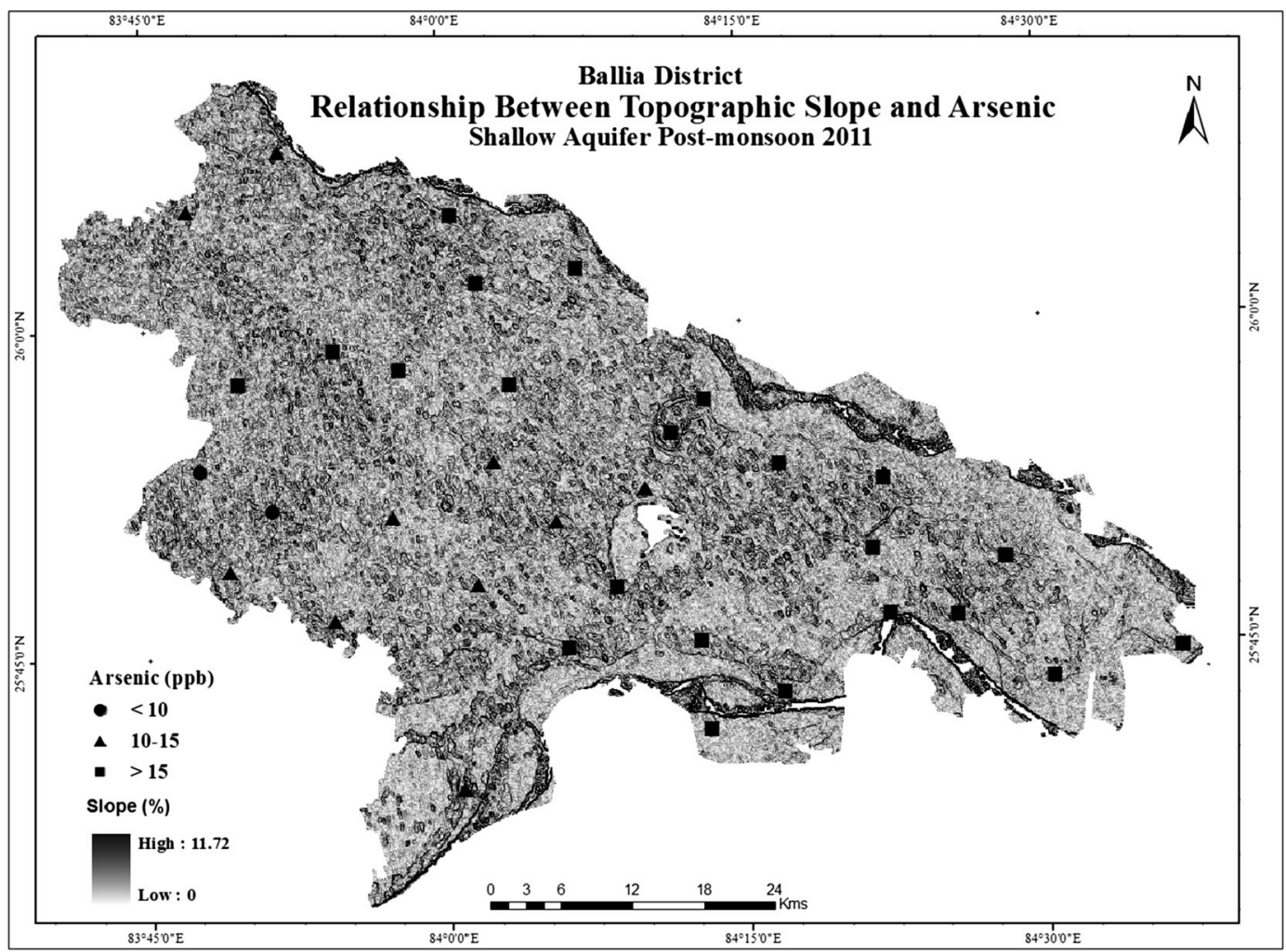

Fig. 7 Relationships between topographic slope and arsenic post-monsoon

Table 2 Relationship between topographic slope and As concentration in shallow aquifer (pre and post-monsoon season)

\begin{tabular}{|c|c|c|c|c|c|c|}
\hline \multirow[t]{2}{*}{ Statistical parameters } & \multicolumn{2}{|c|}{ As $<10 \mathrm{ppb}$} & \multicolumn{2}{|c|}{ As $10-15 \mathrm{ppb}$} & \multicolumn{2}{|c|}{ As $>15 \mathrm{ppb}$} \\
\hline & Pre & Post & Pre & Post & Pre & Post \\
\hline Number of As data points & 2 & 2 & 5 & 10 & 27 & 22 \\
\hline As-affected area (in sq km) & 175 & 175 & 439 & 877 & 2367 & 1929 \\
\hline Range (slope in \%) & $1.82-1.69$ & $1.18-1.69$ & $1.13-1.93$ & $0.46-1.93$ & $0.15-0.72$ & $0.15 .-1.72$ \\
\hline Mean slope in $\%$ & 1.43 & 1.43 & 1.37 & 1.10 & 0.66 & 0.63 \\
\hline $95 \%$ confidence interval & 0.51 & 0.51 & 0.42 & 0.39 & 0.27 & 0.21 \\
\hline Standard deviation & 0.25 & 0.25 & 0.29 & 0.41 & 0.40 & 0.41 \\
\hline
\end{tabular}

\section{Water-table and As concentration}

The relationship between groundwater As and watertable in Ballia is shown in Figs. 8, 9. The statistical analysis showed that $175 \mathrm{sq} \mathrm{km}$ area had As concentrations within the permissible limit $(<10 \mathrm{ppb})$ which is found in areas where mean water-table is 62.5 and 59.5 feet in pre and post monsoon, respectively (Table 3 ). The correlation 


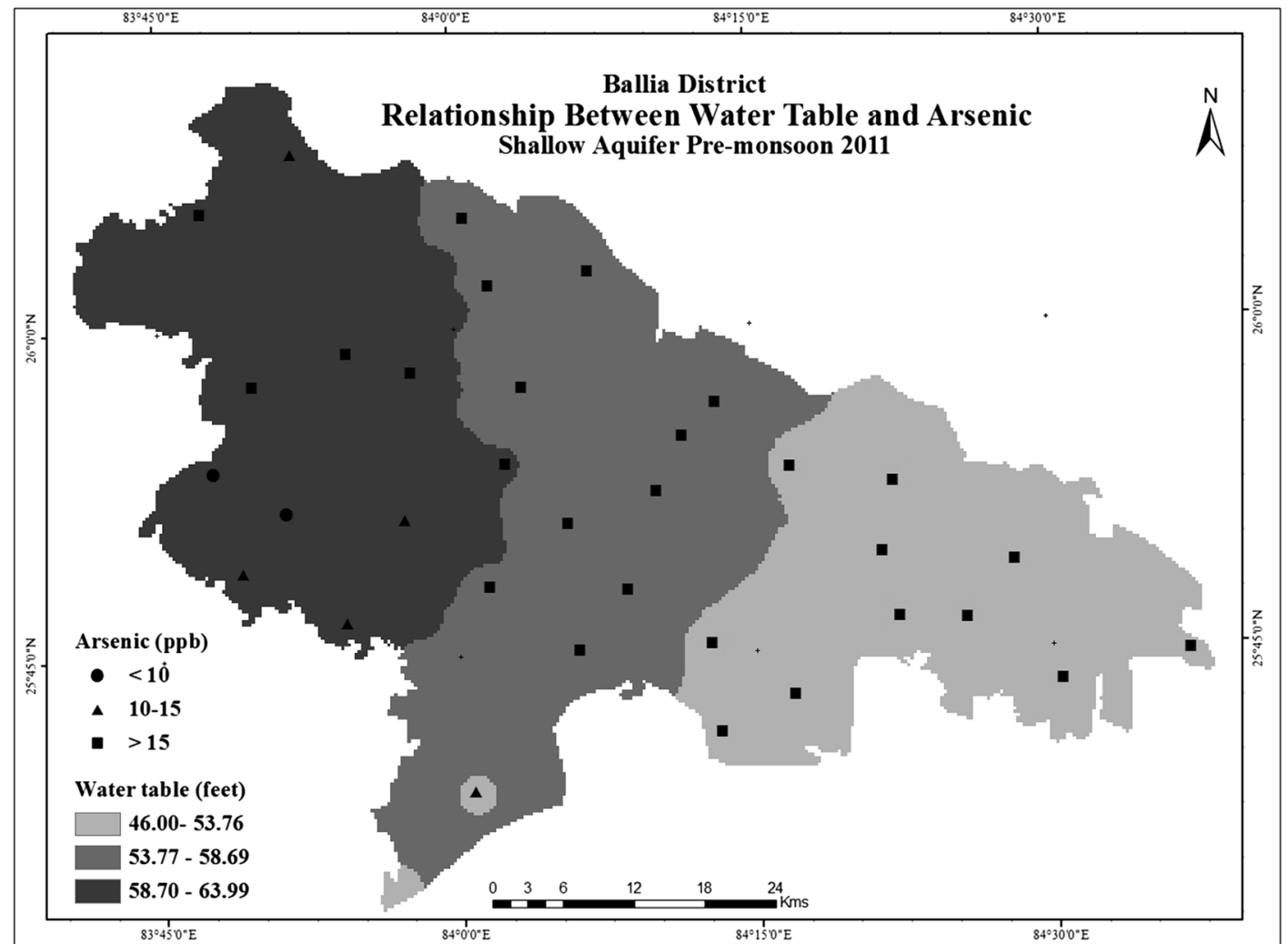

Fig. 8 Relationships between water table and arsenic pre-monsoon

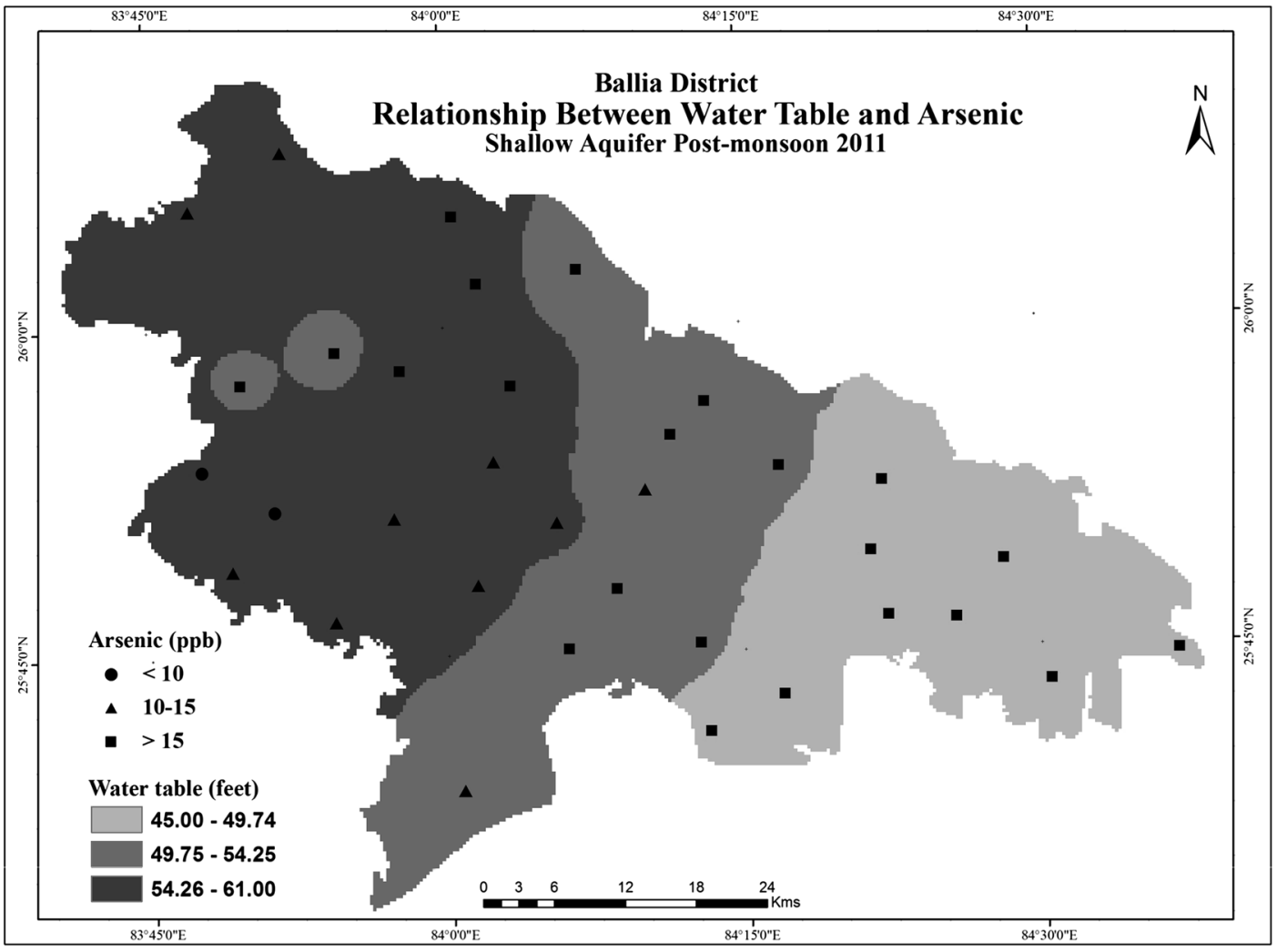

Fig. 9 Relationships between water table and arsenic post-monsoon 
Table 3 Relationship between water table and As concentration in shallow aquifer (pre and post-monsoon season)

\begin{tabular}{|c|c|c|c|c|c|c|}
\hline \multirow[t]{2}{*}{ Statistical parameters } & \multicolumn{2}{|c|}{ As $<10 \mathrm{ppb}$} & \multicolumn{2}{|c|}{ As $10-15 \mathrm{ppb}$} & \multicolumn{2}{|c|}{ As $>15 \mathrm{ppb}$} \\
\hline & Pre & Post & Pre & Post & Pre & Post \\
\hline Number of As data points & 2 & 2 & 5 & 10 & 27 & 22 \\
\hline As-affected area (in sq km) & 175 & 175 & 439 & 877 & 2367 & 1929 \\
\hline Range (water-table in feet) & $61-64$ & $58-61$ & $53-61$ & $50-60$ & $47-62$ & $45-58$ \\
\hline Mean water-table in feet & 62.5 & 59.5 & 58.8 & 55.8 & 54.37 & 50.60 \\
\hline $95 \%$ confidence interval & 0.71 & 0.71 & 0.68 & 0.61 & 0.42 & 0.37 \\
\hline Standard deviation & 1.5 & 1.5 & 2.92 & 2.71 & 3.90 & 3.71 \\
\hline
\end{tabular}
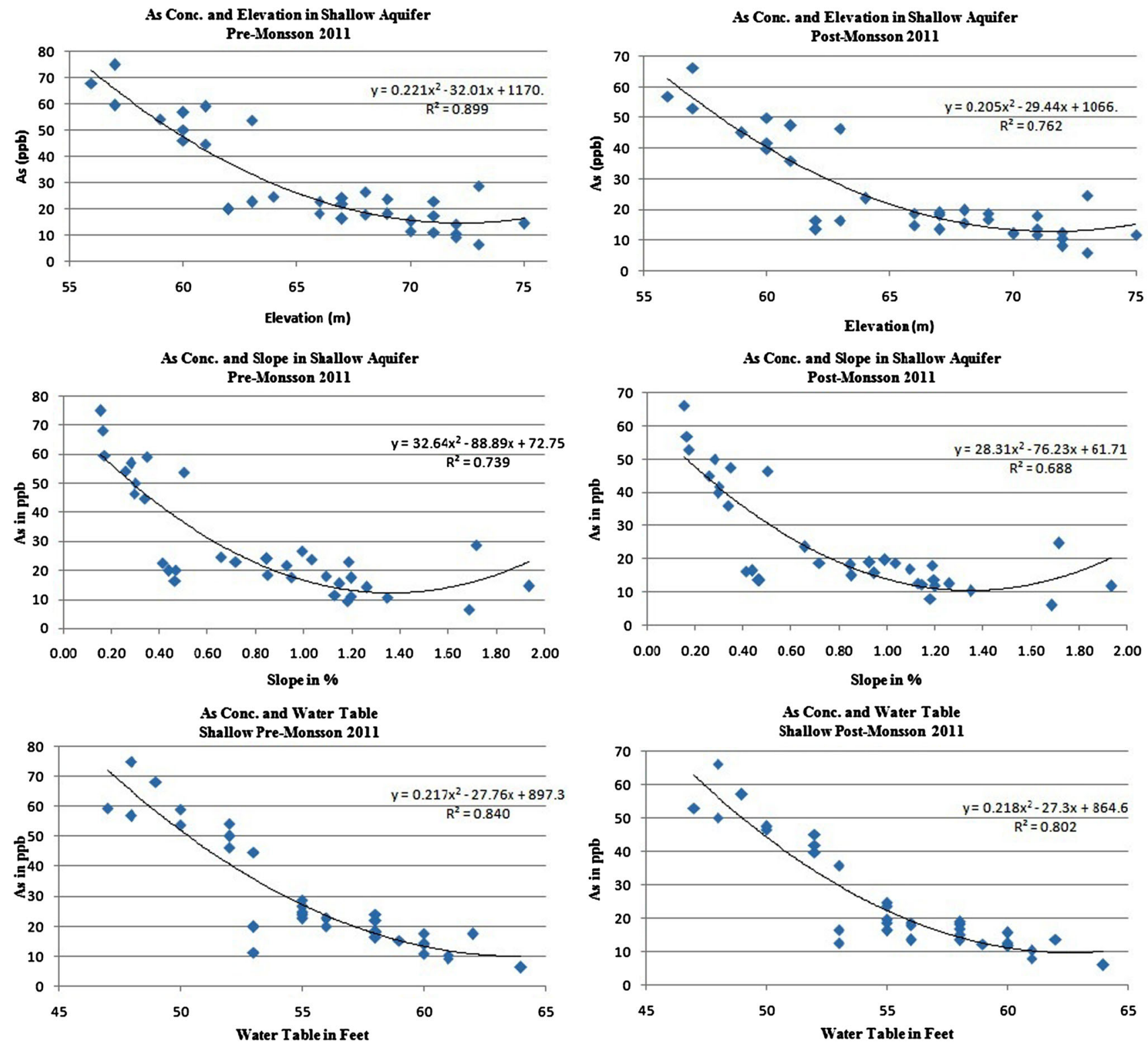

Fig. 10 Scatter plot to draw out the relationships

coefficients $\left(\mathrm{r}^{2}\right)$ between As and water-table were 0.84 and 0.80 in pre and post monsoons (Fig. 10). The scatter plots between As and water-table shows the association of high

As with low water-table in the district. About 59 per cent water sample were have As above $50 \mathrm{ppb}$ at the depth of less than $30 \mathrm{~m}$ (Chowdhury et al. 1999). At low horizontal 
hydraulic gradients and under reducing conditions, As is released in groundwater by microbial activity, causing widespread contamination in the low-lying deltaic and floodplain areas (Shamsudduha et al. 2008). The relationship between As and water-table was non-linear which suggested that these two variables have positive correlation. About Areas of 2367 and $1929 \mathrm{sq} \mathrm{km}$ of aquifers were highly contaminated ( $>15 \mathrm{ppb})$ with the mean watertable of 54.37 and 50.60 feet in pre and post monsoons, respectively (Table 3). Groundwater table map shows that the water level is higher in the north-western part of Ballia district, where surface elevations were also high. This means that the water-table was inversely related with As distribution. Therefore, aquifers with low concentrations of As were also found within high water-table areas where as high As were found in the areas of low water table. Water table is also inversely related to surface elevation; therefore, the areas of low water-table were found where surface elevation is low. In the study area water-tables are fairly low in low lying areas of younger alluvium plains of the Ganga and Ghaghara rivers, where elevations are low. It is observed that the groundwater flow in the aquifers towards the general direction of the Ganga and Ghaghara rivers.

\section{Conclusions}

The study showed that groundwater As concentration surface elevation, topography and water table have strong positive correlation the relationship is non-linear and these three are inversely correlated. Therefore, high As values were found in the areas which are relatively flat area. The study showed that high As is, generally, found in areas of low surface elevation, low slopes, and low groundwater levels on a regional-scale in the district. High As values were found in the areas of low about more than $2800 \mathrm{sq} \mathrm{km}$ areas have As $>15 \mathrm{ppb}$ where the mean slope of $64.33 \mathrm{~m}$ in entire district which is a serious concern and due this a large population is getting affected due to As in ground water. It is understood that the As concentration in groundwater is controlled by the regional topography, slope, water table which depends on rainfall and withdrawal.

Acknowledgments The authors are thankful to Ministry of Environment and Forests (MoEF), Government of India, New Delhi for funding the project, Ref. No. F. No. 13/6/2008-RE.

\section{References}

Acharyya SK, Shah BA (2007) Groundwater As contamination affecting different geologic domains in India-a review: influence of geological setting, fluvial geomorphology and Quaternary stratigraphy. J Environ Sci Health 42:1795-1805

Aggarwal PK, Basu AR, Poreda RJ (2000) Isotope hydrology of groundwater in Bangladesh: Implications for characterisation and mitigation of arsenic in groundwater, TC Project BGD/8/ 016. Int. At. Energy Agency, Vienna

Ahamed S, Sengupta MK, Mukherjee A, Hossain MA, Das Nayak B, Pal A, Mukherjee SC, Pati S, Dutta RN, Chatterjee G, Mukherjee A, Srivastava R, Chakraborti D (2006) Arsenic groundwater contamination and its health effects in the state of Uttar Pradesh (UP) in upper and middle Ganga plain, India: a severe danger. Sci Total Environ 370:310

Ali I, Gupta VK, Khan TA, Asim M (2012a) Removal of arsenate from aqueous solution by electro coagulation method using AlFe Electrode. Int J Electrochem Sci 7:1898-1907

Ali I, Rahman A, Khan TA, Alam SD, Khan J (2012) Recent Trends of Arsenic Contamination in Groundwater of Ballia District, Uttar Pradesh, India. Gazi Univer J Sci 25(4): 853-861 (ISSN No. 1303-9709)

Brammer H, Ravenscroft P (2009) Arsenic in groundwater: a threat to sustainable agriculture in South and South-east Asia. Environ Int 35:647-654

Buschmann J, Berg M, Stengel C, Sampson ML (2007) Arsenic and manganese contamination of drinking water resources in Cambodia: coincidence of risk areas with low relief topography. Environ Sci Technol 41:2146-2152

Centre for Science and Environment (CSE) (2005) A Briefing paper on Arsenic Contamination of groundwater. Nector to Poison, New Delhi

Chakraborti D, Rahman MM, Chowdhury UK, Paul K, Sengupta MK, Lodh D (2002) Arsenic calamity in the Indian subcontinent: what lessons have been learned? Talanta 59:3-22

Chakraborti D, Sengupta MK, Rahman MM, Ahamed S, Chowdhury UK, Hossain MA, Mukherjee SC, Pati S, Saha KC, Dutta RN, Quamruzzaman Q (2004) Groundwater arsenic contamination and its health effects in the Ganga-Meghna-Brahmaputra plain. J Environ Monit 6:74N-83N

Chauhan VS, Nickson RT, Chauhan D, Iyengar L, Sankararamakrishnan N (2009) Ground water geochemistry of Ballia district, Uttar Pradesh, India and mechanism of arsenic release. Chemosphere 75(1):83-91

Chauhan VS, Yunus M, Sankararamakrishnan N (2012) Geochemistry and mobilization of arsenic in Shuklaganj area of KanpurUnnao district, Uttar Pradesh, India. Environ Monit Assess 184:4889-4901

Chowdhury TR, Basu GK, Mandal BK, Biswas BK, Samanta G, Chowdhury UK, Chanda CR, Dilip D, Roy SL, Saha KC, Roy S, Kabir S, Quamruzzaman Q, Chakraborti D (1999) Arsenic poisoning in the Ganges delta. Nature 401:545-546

Census of India (2001). http://www.census2011.co.in/census/district/ 564-ballia.html

Dhar RK, Biswas BK, Samanta G, Mandal BK, Chakraborti D, Roy S, Jafar A, Islam A, Ara G, Kabir S, Khan AW, Ahmed SA, Hadi SA (1997) Groundwater arsenic calamity in Bangladesh. Curr Sci India 73:48-59

Ghosh NC, Singh RD (2009) Groundwater arsenic contamination in India: vulnerability and scope for remedy. Technical Papers included in the special session on Ground water in the 5th Asian Regional Conference of INCID, December 9-11, 2009 held at Vigyan Bhawan, New Delhi

Gunduz O, Simsek C, Hasozbek A (2010) Arsenic pollution in the groundwater of Simav Plain, Turkey: its impact on water quality and human health. Water Air Soil Pollut 205:43-62

Hoque MA, Burgess WG, Shamsudduha M, Ahmed KM (2011) Delineating low-arsenic groundwater environments in the Bengal Aquifer System, Bangladesh. Appl Geochem 26:614-623 
Hossain MM, Piantanakulchai M (2013) Groundwater arsenic contamination risk prediction using GIS and classificationtree method. Eng Geol 156:37-45

Jarvis A, Reuter H I, Nelson A, Guevara E (2006) Hole-filled SRTM for the globe Version 3, available from the CGIAR-CSI SRTM 90 m Database. http://srtm.csi.cgiar.org. Accessed 20 Oct 2015

Kinniburgh DG, Smedley PL (2001) Arsenic contamination of groundwater in Bangladesh,final report. (eds) Keyworth: British Geological Survey. 2:175-185. (BGS technical report no. WC/ 00/19)

Klump S, Kipfer R, Cirpka OA, Harvey CF, Brennwald MS, Ashfaque KN, Badruzzaman ABM, Hug SJ, Imboden DM (2006) Groundwater dynamics and arsenic mobilization in Bangladesh assessed using noble gases and tritium. Environ Sci Technol 40:243-250

Mahimairaja S, Bolan NS, Adriano DC, Robinson B (2005) Arsenic contamination and its Risk management in complex Environmental settings. Adv Agron 86, Elsevier Inc

Mukherjee A, Fryar AE, Howell PD (2007) Regional hydrostratigraphy and groundwater flow modeling in the arsenic-affected areas of the western Bengal basin, West Bengal, India. Hydrogeol J 15(7):1397-1418

Rahman A, Khan J, Alam SD, Ali I, Khan TA, Sharma R (2015a) Geo-chemical Analysis of Arsenic in Medium Aquifers and its Relation with Physical Parameters: A Study of Ballia District, India. J Water Res Eng Manag 2(1): 38-50 (ISSN. 2349-4336)

Rahman A, Khan J, Alam SD, Ali I, Khan TA, Sharma R (2015b) Geochemical Assessment and Modelling of Groundwater Arsenic with Land Surface Features in Ballia District using Satellite Data and GIS. J Remote Sens GIS 6(2):1-15 (ISSN: 2230-7990)
Samadder SR (2010) Impact of Arsenic pollution in drinking water on life expectancy: a GIS study. KSCE J Civ Eng 14(5):681-691

Shamsudduha M (2004) Geostatistical and multivariate statistical analyses on the widespread arsenic problem in the groundwater of Bangladesh. M.Sc, University of Technology Sydney, NSW, Australia

Shamsudduha M, Uddin A (2007) A Quaternary shoreline shifting and hydrogeologic influence on the distribution of groundwater arsenic in aquifers of the Bengal Basin. J Asian Earth Sci 31:177-194

Shamsudduha M, Uddin A, Saunders JA, Lee M-K (2008) Quaternary stratigraphy, sediment characteristics and geochemistry of arsenic-contaminated alluvial aquifers in the Ganges-Brahmaputra floodplain in central Bangladesh. J Contam Hydrol 99(1-4):112-136. doi:10.1016/j.jconhyd.2008.03.010

Shamsudduha M, Marzen LJ, Uddin A, Lee M-K, Saunders JA (2009) Spatial relationship of groundwater arsenic distribution with regional topography and water-table fluctuations in the shallow aquifers in Bangladesh. Environ Geol 57(7):1521-1535. doi:10. 1007/s00254-008-1429-3

Stute M, Zheng Y, Schlosser P, Horneman A, Dhar RK, Datta S, Hoque MA, Seddique AA, Shamsudduha M, Ahmed KM, van Geen A (2007) Hydrological control of As concentrations in Bangladesh groundwater. Water Resour Res 43(9):W09417

Tripathi PK (2008) District brochure of Ballia district A.A.P.: 2007-2008 [Online]. Central Ground Water Board, New Delhi. http://cgwb.gov.in/documents/papers/incidpapers/Paper\%208\% 20-\%20Ghosh.pdf. Accessed 20 Oct 2015

USGS, 2002. Shuttle Radar Topography Mission (SRTM) Elevation Dataset, Sioux Falls, South Dakota, http://seamless.usgs.gov. Accessed 24 Apr 2014 